\title{
Corporate entrepreneurship orientation and the pursuit of innovating opportunities in Botswana
}

\author{
Melodi Botha: Department of Business Management, University of Pretoria, \\ Michael David Nyanyom: M Phil Student (Entrepreneurship and Small Business Management) University \\ of Pretoria
}

\begin{abstract}
Synopsis
Purpose and objectives - A causal relationship between the independent variable (introduction of innovation) and the dependent variable (Corporate Entrepreneurship orientation) is explored by addressing the question: Do companies in Botswana have a corporate entrepreneurship (CE) orientation that leads them to pursue innovating opportunities? The primary objective is to investigate how CE orientation in companies in Botswana is linked to individual employees' pursuit of innovation within corporate boundaries. Secondary objectives are to identify the prerequisites and factors of CE orientation, individual employees' perceptions and the importance of innovation factors in established companies.
\end{abstract}

Problem investigated - To determine whether existing firms in Botswana represent the concept of an entrepreneurial company within the sphere of corporate entrepreneurship by pursuing innovating opportunities. The intention is to identify the knowledge, attitudes and beliefs of individuals as potential corporate entrepreneurs, their ability to be innovative and how such innovation is brought to fruition.

Design and methodology - To obtain quantifiable measures of the link between CE orientation and innovation, a quantitative approach is used: a formalised, cross-sectional research design. The sample consists of 100 individuals at supervisory levels and above in large corporate companies, from eight different provinces in Botswana. A research instrument is used and convenience sampling employed. Factor analysis is performed on the questionnaire to determine its validity and reliability. A Pearson correlation coefficient test is conducted on the three factors identified in factor analysis. The chi-square test and T-test (Mann-Whitney $U$ test) are used to illustrate the statistically significant differences between the different variables and factors.

Findings and implications - This paper proves the inextricable link between CE orientation and the pursuit of innovation as a conduit to enhancing entrepreneurial activities in companies in Botswana. The results confirm that companies with an inherently high CE orientation receive a higher benefit from the exploitation of innovation, which improves the rate of innovation flows in the companies.

Value of the research - This paper strives to make a significant contribution to the field of CE orientation in Africa, as no other studies appear to have been done in this particular area in Botswana. Furthermore, this study introduces six CE orientation drivers that companies need if they are to become entrepreneurial. For companies in Botswana to be innovative, it is therefore necessary for CE orientation to become part of the company's culture.

Key words: Corporate entrepreneurship orientation, corporate entrepreneurship orientation drivers, innovating opportunities, opportunity identification, opportunity recognition and exploitation.

\section{INTRODUCTION}

Changes in the business environment and management philosophy have led to an increasing number of companies hh demanding internal entrepreneurship (Christensen, 2004:302). Internal entrepreneurship, or corporate entrepreneurship (CE) as it is widely known, is a concept linked to the entrepreneurial orientation of a company. Zimmerer and Scarborough (1996:32) explain that entrepreneurial orientation creates a positive atmosphere for employees to foster new ideas and encourages them to act upon the ideas. The employees thus act as entrepreneurs within the context of a company. Entrepreneurship within the corporate environment can be seen as the effort to extend a company's competitive advantage (Ferreira, 2002:2). This advantage is achieved through internally generated innovations that significantly increase competition within the industry or that create entirely new industries. Carter and Jones-Evans (2000:242) say that many large companies have had to adopt more innovative and enterprising approaches so as to compete effectively in a dynamic and fast-changing world market, and that it therefore becomes essential to develop entrepreneurship within a corporate environment. Mourdoukoutas and Papadimitriou (2002:1) say this can release the imagination, ingenuity and creativity of the individual 
and the group to create new products, processes and forms in the company. The growing body of CE literature depicts CE as enhancing employees' innovative abilities and thus increasing corporate success (Pinchot, 1985:3; Kuratko, Montagno \& Hornsby, 1990:49; Hornsby, Kuratko \& Zahra, 2002:254; Burns, 2005:5).

In Botswana it appears that no research has been done in the field of CE. Mbendi Information Services (2008:1) states that Botswana has one of the strongest economies in Africa and one of the world's highest growth rates. Furthermore, its government 'has managed the country's resources prudently and has kept its recurrent expenditure within its revenue, allowing for investment in human and physical capital'. This study to explore the country's human capital by focusing on CE orientation in companies in Botswana is therefore timely.

Thus, as far as could be determined, this is the first study done in the field of CE orientation in Botswana. The purpose of the study was to determine whether companies in Botswana have a corporate entrepreneurship orientation and, if they do, whether it results in the pursuit of innovative opportunities. The study attempted to identify the prerequisites and factors of CE orientation and the individual employees' perceptions, and to assess the importance of innovation factors in established companies. The focus was on the individual entrepreneurs within a company. The inter-linkage between innovation and CE orientation variables was explored in order to create a framework for the study. The paper postulates that these variables are connected and positively correlated with each other. It is suggested that the higher the company's CE orientation, the higher the level of innovation will be. The framework is shown in Figure 1. It identifies the variables that, when put together, promote the level of entrepreneurial activity in a corporate setting and consequently the CE orientation.

Figure 1: A framework linking corporate entrepreneurship with innovation

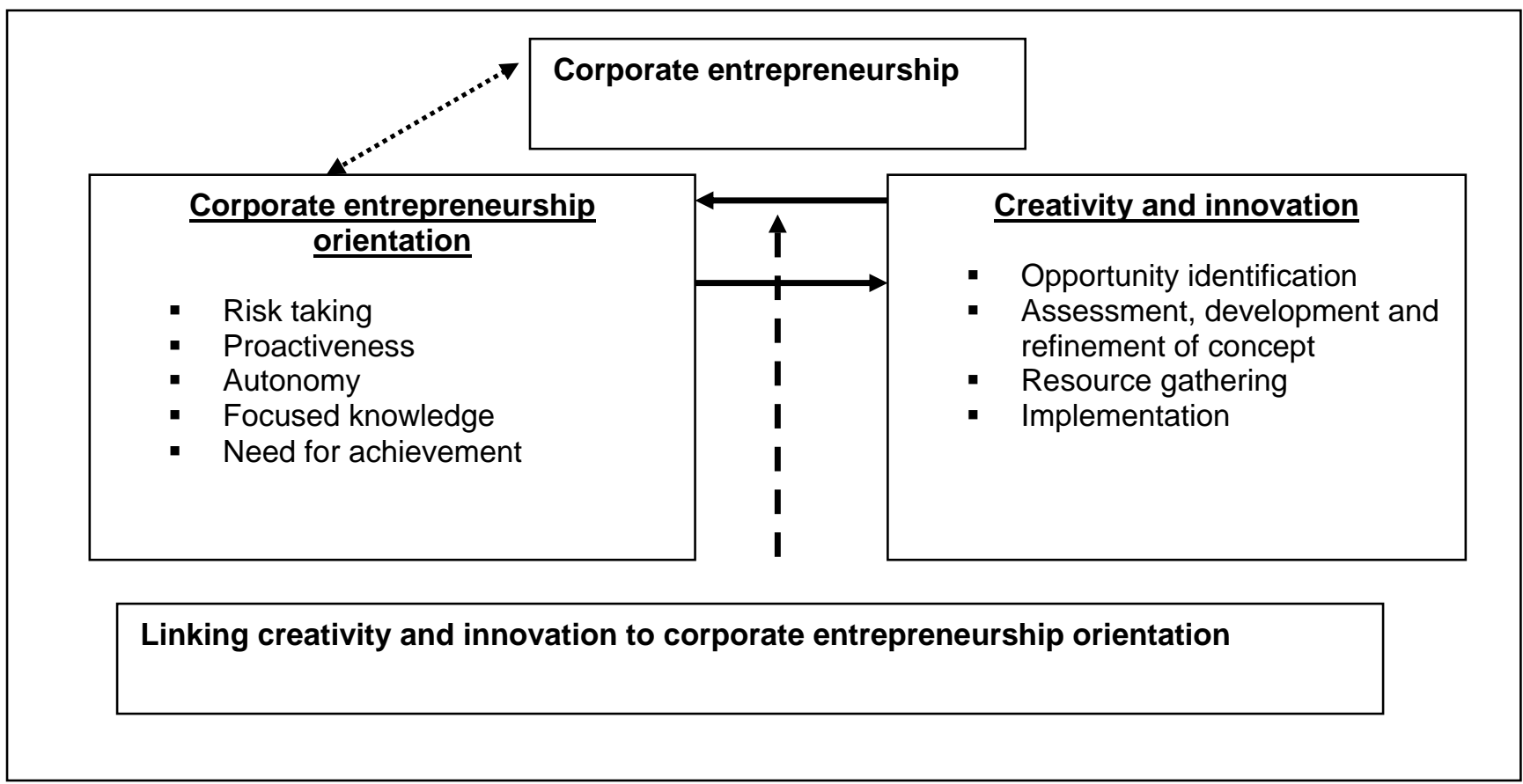

The rest of the paper is organised as follows. The paper first reviews the CE literature, then presents the methodology and the research design, research objectives and hypotheses. It discusses the validity and reliability of the measuring instrument and several statistical tests, after which the findings are presented. The paper concludes with the discussion of the findings and finally offers a conclusion and recommendations. 


\section{THE CORPORATE ENTREPRENEURSHIP LITERATURE}

The review that follows defines and examines the three concepts that provide the model for the study: corporate entrepreneurship (CE), CE orientation and innovation.

\section{Corporate entrepreneurship}

The term 'corporate entrepreneurship' is used to describe entrepreneurial behaviour inside established medium and large companies. CE adopts behavioural styles and practices that challenge bureaucracy and encourage innovation. It stimulates innovation within the company through the exploration and exploitation of new opportunities (Morris \& Kuratko, 2002:31; Thornberry, 2003:330; Antoncic \& Hirsh, 2003:9; McFadzean, O'Loughlin \& Shaw, 2005:351). Zahra (1996:1714) notes that CE also includes attitudes and actions that enhance a company's ability to seize opportunities, take risks and innovate. To understand $C E$, it is important to look at the role of the individuals who show evidence of entrepreneurship within the corporate setting. Burns (2005:134) defines intrapreneurship 'as a concept used to describe the individual charged with pushing through innovations within larger companies, in an entrepreneurial fashion'. The terms internal entrepreneurship, CE and intrapreneurship are often used interchangeably.

\section{Corporate entrepreneurs and corporate enterprises}

Thornberry (2003:331) describes intrapreneurs or corporate entrepreneurs as those who bring to bear the mindset and behaviours characteristic of external entrepreneurs and transpose them to an existing and usually large corporate setting. Christensen (2004:306), however, suggests that the concept is still in search of a clear definition. Unlike South Africa, Botswana does not have statutes that specifically identify what 'corporate company' means in quantitative and qualitative terms. However, it does have a Ministry of Commerce and Industry (1999:3) policy document on small business that authoritatively provides quantitative measures of small and medium sized enterprises: it says they are those with a work force of fewer than 25 and 100 employees respectively. This paper therefore uses a working definition of 'corporate enterprise' as an organisation that has more than 100 employees.

\section{CE orientation}

Dess and Lumpkin (2005:3) refer to entrepreneurial orientation as the strategy-making practices and processes that managers engage in to identify and create venture opportunities, and Morris and Kuratko (2002:39) add that entrepreneurship orientation provides a platform to empower employees in decision making. From their review of the work of several researchers, there emerge five drivers of entrepreneurial orientation, identified as: innovativeness, risk taking, proactiveness, need for achievement (competitive aggressiveness) and autonomy (Morris \& Kuratko, 2002:39; Nieman \& Pretorius, 2004:20; Rauch, Wiklund, Frese \& Lumpkin, 2004:165).

Dess and Lumpkin (2001:430) argue that entrepreneurial orientation may occur in different dimensions, better known as drivers, and some researchers suggest that these drivers tend to vary independently rather than co-vary (Rauch et al., 2004:164). This observation is fundamental to this paper, as the study constructs the drivers (explained below) as moderating variables to the CE orientation concept. For this reason, it is expected that correlations will be derived that will tend to reflect and measure their relationship with the independent variable.

\section{CE orientation drivers}

The factors that drive corporate entrepreneurs to explore or exploit opportunities and lead them to create new products or discover new processes are shown in Figure 2 and discussed in detail below. These are the drivers identified in the research reviewed above, with the addition of a sixth, focused knowledge, since the accumulation of knowledge capital is regarded as a reliable and lasting source of competitive advantage. The first driver, innovativeness, is discussed in further depth below. 
Figure 2: CE drivers

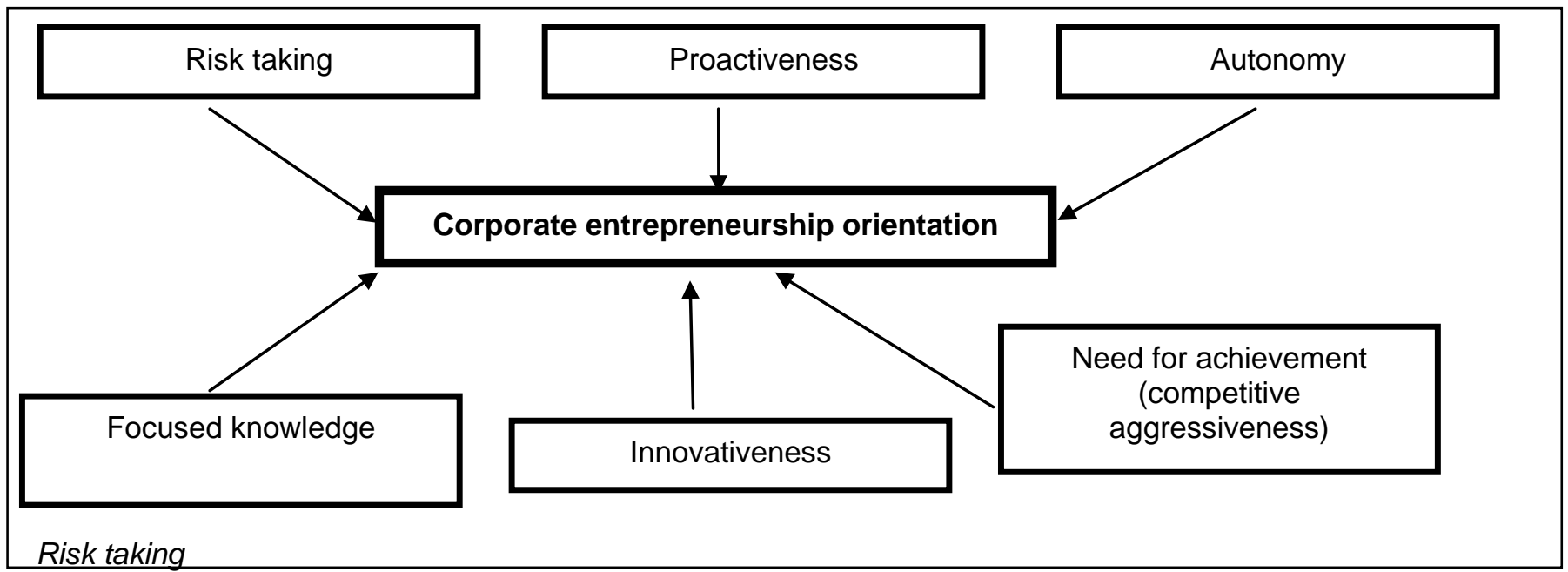

The work of Cantillon (1931[1755]:47) made a significant contribution to the field of entrepreneurship. He defined an entrepreneur as a person who bears the risk of profit or loss of a venture. Consequently, several authors see risk taking as a fundamental element of entrepreneurship. Morris and Kuratko (2002:41) say it 'involves a willingness to pursue opportunities that have a reasonable likelihood of producing losses or significant performance discrepancies'. They say that moderate and calculated risk taking can be viewed as an individual-level trait that involves a willingness to pursue opportunities that have an effect on the company. Some aspects of the risk-taking propensity are the quick pursuit of opportunities, fast commitment of resources, bold actions and experimentation (Covin \& Slevin, 1991:7; Lumpkin \& Dess, 1996:135; Timmons \& Spinelli, 2003:172; Hisrich, Peters \& Shepherd, 2004:225).

Proactiveness

To be proactive is to anticipate future needs and take action on this basis. Burns (2005:28) notes that entrepreneurs tend to be proactive in the sense that they seek out opportunities and do not rely on luck. He states that they act quickly and decisively to make the most of opportunity before someone else does, as this is the only way to achieve success. Morris and Kuratko (2002:44) say that proactiveness is concerned with implementation, with doing whatever is necessary to bring an entrepreneurial concept to fruition'. This study noted that proactiveness involves pioneering and initiative taking, a commitment to implementing new business processes which are designed to cultivate new markets for the firm's offerings.

\section{Need for achievement}

McClelland (1976:207) suggests that achievement motivation includes doing things in a new and better way and taking calculated risks. Achievers initiate successful actions by setting and achieving standards previously not met. This involves working relentlessly towards the set standards and obtaining feedback on the status of the work done. Achievers tend to shun routine tasks and concentrate on aspects that are challenging. Subjects with a high need for achievement (also known as competitive aggressiveness) do not overestimate their probability of success but innovate actively and constantly. They work harder when it counts for personal achievement, especially when their personal efforts will make a difference to the outcomes. Fynn (2005:29) notes that 'high need for achievement leads people, and in particular entrepreneurs, to tend to act in ways that best allow them to fulfil the entrepreneurial and leadership role successfully'. Entrepreneurs are driven by a strong inner need to achieve and they enjoy doing challenging work, often to the exclusion of other things (Burns, 2005:29). 


\section{Autonomy}

Autonomy means 'independent action by an individual or team aimed at bringing forth a business concept or vision and carrying it through to completion' (Dess \& Lumpkin, 2001:429). These authors note that firms that wish to explore venture opportunities must create an environment 'where innovation team members are free to explore possibilities without the influence of strategic norms or organisational traditions that may impede the discovery process' (Dess \& Lumpkin, 2005:4).

Voss, Voss and Moorman (2005:1136) suggest that entrepreneurial behaviour is often 'generative and creative, involving the autonomous actions of organisational actors'. A policy of employee autonomy is a commitment to encouraging employees to be self directed and independent in the generation and implementation of novel ideas. They argue that it is for this reason that autonomy is thought to be an essential element of the entrepreneurial orientation construct.

Given these viewpoints, the paper makes the observation that autonomy is a dimension that would greatly influence CE orientation. Entrepreneurs working within corporate borders need to feel autonomous in what they do, to have the latitude to explore or exploit innovative ideas free from organisational norms. It is for this reason that the paper suggests that entrepreneurs with a high level of autonomy will lead to higher levels of innovation in a company.

\section{Focused knowledge}

Zikmund (2003:21) states that 'knowledge is a blend of information, experiences and insights that provide a framework that can be thoughtfully applied when assessing new information or evaluating certain situations'. Burns (2005:63) postulates that entrepreneurs learn by doing, and they learn quickly not to repeat mistakes but to capitalise on success. The author adds that in this way knowledge is 'transferred continuously, quickly and without barriers'. The focus on the learning process will therefore rest with those individuals who are more closely involved in the introduction of new products or services (Ireland, Hitt \& Sirmon, 2003:975).

Dovey and White (2005:247) advance the view that creating an innovation culture where knowledge is valued and shared effectively is one of the most difficult challenges faced in practice. Fiet (2002:93) contends that possessing the competence to discover and exploit information that is not generally accessible may hold the key to creating new wealth. He argues that prior knowledge determines entrepreneurs' competence to make a specific discovery and circumscribes how and where they can search. Policy makers must appreciate that innovation is about people as well as product and processes (Thompson, 2004:1093). It is thus important to identify those people with great potential and to offer them encouragement. Attention must be paid to thinking processes as well as managed innovation processes. From the discussions above, the paper observes that focused knowledge appears to be an important lubricator of organisation learning. In an atmosphere where it is prevalent, it is important to inculcate selfdirectedness and independence so as to generate and implement new ideas, thus leading to a high level of innovation.

\section{Creativity and innovation within corporate borders}

Many authors view creativity and innovation as two major components of entrepreneurship. They have thus stressed the importance of creativity in the process of invention (Bolton \& Thompson, 2000:14; Struwig 2003:352). Figure 3 draws a distinction between innovation, creativity and entrepreneurship. It shows that creativity means getting an idea, while innovation means implementing it. Entrepreneurship, on the other hand, is seen as requiring innovation (Struwig, 2003:352). The dynamism of the three concepts clearly indicates that creativity precedes innovation, as innovation cannot exist without creativity. It also establishes that the act of entrepreneurship is the driving force in bringing innovation to fruition. 
Figure 3: Distinction between creativity, innovation and entrepreneurship

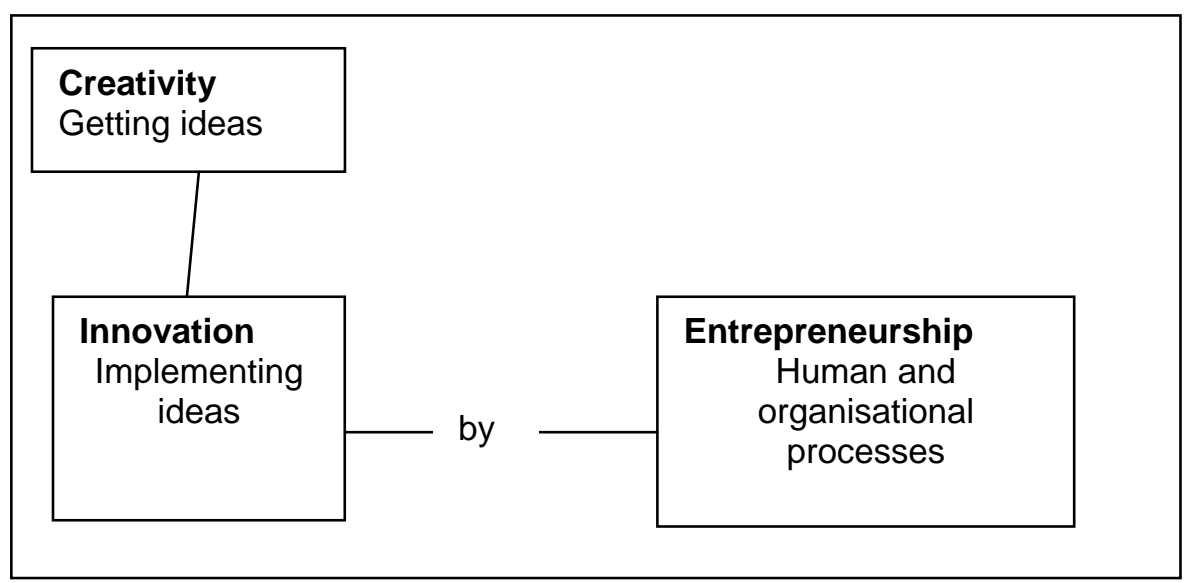

Source: Struwig (2003:352)

\section{Pursuing opportunities for innovation}

Innovation is considered the first dimension that characterises an entrepreneurial company (Kuratko \& Welsch, 1994:359; Morris \& Kuratko, 2002:39). Personal initiatives create an atmosphere of innovation, and innovative programmes help build an entrepreneurial company. Drucker (2001:278) proposes that the entrepreneur always searches for change, responds to it, and exploits it as an opportunity based on purposeful innovation. Opportunity recognition can therefore be seen as the core attribute of entrepreneurship orientation. The innovative use of resources to pursue opportunities therefore becomes essential if a company is to thrive. Continuous innovation must flow through the company unabated. The entrepreneur's attitudes, vision and actions enable the company to adapt, develop and innovate.

\section{Linking CE orientation and the pursuit of opportunities for innovation}

The literature review established the fact that entrepreneurship is intricately linked with innovation. Most researchers believe that firms with a strong entrepreneurship orientation will pursue innovation goals more efficiently (Dess \& Lumpkin, 2005:4; Pavitt, 2005:88). Dess and Lumpkin (2005:3) suggest that firms that exhibit a strong entrepreneurial orientation may have an advantage when it comes to understanding innovation via exploration and exploitation activities, and McGrath and Macmillan (2000:232) point out that many firms that are successful innovators attribute much of their success to an entrepreneurial orientation.

Zhao (2005:25) investigates the relationship between entrepreneurship and innovation and concludes that entrepreneurship and innovation are positively related to each other and interact to help a company to flourish and to pursue opportunities. He further establishes that entrepreneurship and innovation are complementary, and a combination of the two is vital to organisational success and sustainability to today's changing environment. Since innovation has to address market needs, corporations require entrepreneurship if they are to achieve commercial success.

To conclude, the literature revealed that the link between CE orientation and innovative opportunities lies in an individual's ability to identify, generate and exploit opportunities within his or her corporate borders.

\section{METHODOLOGY}

Since the paper sought to obtain quantifiable measures of the link between CE orientation and innovation, it used a quantitative approach: a formalised, cross-sectional research design. The sample consisted of 100 individuals at supervisory and above-supervisory levels in large corporate companies in Botswana, from eight different provinces in Botswana. A convenience sampling technique was applied to the sample frame whereby 45 different companies were selected, and the questionnaires were distributed to 110 respondents within those companies. The 100 returned questionnaires represent a $90 \%$ response rate. 
Factor analysis was performed on the questionnaire and the responses received were used to determine the two factor labels: pursuit of innovation and CE orientation. Out of the factor labels three factors were generated and these are presented in Table 2.

\section{Research design and objectives}

The study explored whether there was a causal relationship between the independent variable (introduction of innovation) and the dependent variable (CE orientation) by addressing the question: Do companies in Botswana have a CE orientation that leads them to pursue opportunities for innovation?

The primary objective was to investigate how CE orientation in companies in Botswana was linked to individual employees' pursuit of innovation within corporate boundaries. Secondary objectives were to identify the prerequisites and factors of CE orientation, individual employees' perceptions and the importance of innovation factors in established companies.

\section{Hypotheses}

The paper formulated two hypotheses to measure the value of the described relationship as follows:

$\mathrm{H} 1$ o Individuals with a low $\mathrm{CE}$ orientation will not pursue innovation opportunities that make companies entrepreneurial.

$\mathrm{H} 1_{\mathrm{a}}$ Individuals with a high CE orientation will pursue innovation opportunities that make companies entrepreneurial.

$\mathrm{H} 2$ o Individuals who have a low perception of the innovative factors will not pursue innovation opportunities that make companies entrepreneurial.

$\mathrm{H} 2_{\mathrm{a}}$ Individuals who have a high perception of the innovative factors will pursue innovation opportunities that make companies entrepreneurial.

The paper builds correlations testable by means of inferential statistical measures based on the factors generated, as in Table 2. The correlations sought are summarised in Table 1.

The study performed a hypothesis-testing procedure whereby the null or alternative hypothesis is accepted or rejected. The one-tailed measure was applied to test the hypothesis and a significance level of 0.05 was used.

Table 1: Correlation sought from the hypotheses

\begin{tabular}{|l|l|}
\hline Correlation sought & Hypothesis \\
\hline The level of introduction of new innovation by individuals with their CE orientation & $\mathrm{H}_{1}$ \\
\hline The level of introduction of new innovation by individuals with their pursuit of innovation & $\mathrm{H}_{2}$ \\
\hline
\end{tabular}

\section{FINDINGS}

The literature review revealed an inherent link between CE orientation and the pursuit of innovation opportunities. This prompted an investigation of the extent of the relationship between these variables as they apply in Botswana. Firstly, the demographics of the sample are presented. Thereafter factor analysis is carried out to determine the reliability and validity of the measuring instrument. Furthermore the onesample chi-square $\left({ }^{2}\right)$ test indicates the significant differences of the different variables. Finally, the t-test and the Mann-Whitney test are carried out by using the three factors: opportunity identification; opportunity generation and exploitation; and CE orientation, that were identified in the factor analysis.

\section{Employee and industry demographics of the sample}

This section summarises the respondents' gender, age group, racial composition, position in the company, and business sector in which their company operates.

The respondents were $78 \%$ male and $22 \%$ female. Men predominate at higher levels (from supervisory level upwards) in corporate circles in Botswana. The respondents' ages ranged from 22 to 65 . Most were in the 31 to 40 age group and these accounted for $47 \%$ of the total number of responses. 
The majority of the respondents (70\%) were black; $15 \%$ were Indian, $14 \%$ were white, and $1 \%$ was coloured. The lack of racial diversity in the corporate companies was probably due to the ongoing localisation programmes currently being implemented.

Concerning the hierarchical position in the companies, responses were received from eight Chief Executive Officers (CEOs) and 42 management level employees. This combined group accounts for $52 \%$ $(n=52)$ of the total respondents and can be compared favourably with the 48 respondents from supervisory level. This equitable distribution is useful, as the paper captures the levels in the company that could significantly influence CE.

The responses received revealed that the employees were engaged in a wide spectrum of industries. Most were in the service/distribution sector (37\%), followed by the manufacturing sector $(21 \%)$, construction sector $(11 \%)$ and banking/financial services sector $(10 \%)$. The results seem to reflect the proportion of corporate companies in Botswana by industry type.

\section{Validity and reliability of the measuring instrument}

The measuring instrument sought to confirm the validity and reliability of the variables under consideration, using exploratory factor analysis. The Cronbach alphas obtained from factor analysis present alpha scores that are used as indicators to determine whether the variables in the questionnaire are reliable or accurate. According to Athayde (2003:10), there is some debate about what constitutes an acceptable alpha score. A summary of over 800 articles of empirical studies using Cronbach alphas found that reported coefficients ranged from 0.600 to 0.999. If an alpha score is high (between 0.600 and 0.999), it indicates that the items tested in the questionnaire are valid and reliable. In this paper, 0.600 was used as the benchmark.

Table 2 summarises the results of the exploratory factor analysis using direct quartimin, an oblique rotation method. Diamantopoulos and Schlegelmilch (2000:216) say that factor analysis aims to 'reduce the original set of variables (grouped together and known as factor labels) into a smaller set of combined variables (called factors)'. The variables contained in the factor label 'pursuit of innovation' were opportunity identification, assessment development and refinement of the concept, and resource gathering and implementation. For the factor label, 'pursuit of innovation', 18 variables were tested. Two factors: opportunity identification; and opportunity generation and exploitation, were obtained from this factor label. The six variables tested in the factor label 'CE orientation' were innovativeness, risk taking, proactiveness, need for achievement, autonomy and focused knowledge. These were summarised as one factor, namely CE orientation.

Table 2: Factor analysis results

\begin{tabular}{|c|c|c|c|}
\hline Factor labels & Factors generated & Eigen values & $\begin{array}{l}\text { Cronbach } \\
\text { alpha }\end{array}$ \\
\hline \multirow{2}{*}{$\begin{array}{l}\text { Pursuit } \\
\text { innovation }\end{array}$} & Opportunity identification (Factor 1 ) & 8.766 & 0.9349 \\
\hline & $\begin{array}{l}\text { Opportunity generation and exploitation } \\
\text { (Factor 2) }\end{array}$ & 1.493 & 0.8092 \\
\hline CE orientation & CE orientation (Factor 3) & 6.257 & 0.8940 \\
\hline
\end{tabular}

To improve the understanding of the above factor labels and factors generated, the study examined the variable indicating the level of introduction of innovations by individuals in their companies. This variable was regarded as important in the study because for innovation to take place within corporate boundaries, the corporate environment must be conducive to supporting innovation.

\section{Correlation of the three factors}

A Pearson correlation coefficient test was conducted on the three factors (Opportunity identification Factor 1; Opportunity generation and exploitation - Factor 2; and CE orientation - Factor 3) and is presented in Table 3. 
Table 3: Pearson product moment correlations among the three factors

\begin{tabular}{|c|c|c|c|}
\hline & Factor 1 & Factor 2 & Factor 3 \\
\hline Factor 1 & 1.00000 & $\begin{array}{l}0.68473 \\
\mathrm{p}<0.0001^{* * *}\end{array}$ & $\begin{array}{l}0.41644 \\
p<0.0001^{* * *}\end{array}$ \\
\hline Factor 2 & & 1.00000 & $\begin{array}{l}0.19322 \\
\text { p } 0.0541\end{array}$ \\
\hline Factor 3 & & & 1.00000 \\
\hline
\end{tabular}

${ }^{*}<0.001$ statistically significant difference $(99 \%$ confidence level)

The purpose of this test is to investigate the correlation and statistical significance of these factors. The greater the difference of the correlation from 0 , the stronger the relationship. The correlations portray a strong statistical association between Factor 1 (Opportunity identification) and 2 (Opportunity generation and exploitation); a moderate one between Factor 1 (Opportunity identification) and 3 (CE orientation); and a weak correlation between Factor 2 (Opportunity generation and exploitation) and 3 (CE orientation). These correlations are described below.

The correlation between opportunity identification and opportunity generation and exploitation is 0.68473 . This means there is a strong positive relationship between these variables, a positive increase in either of the factors occasioning an equal and corresponding increase in the other. Thus individuals who tend to identify opportunities in companies tend to bring to fruition motions of generating and exploiting these innovations at a high level. This correlation has a reliability coefficient of $p<0.0001$, which indicates that this correlation is significant at a $1 \%$ level.

The correlation coefficient of the correlation between CE orientation and opportunity identification is noted as positive at 0.41664 . This means there is a modest positive relationship between these factors. In this situation, an increase in one factor will occasion an equally moderate increase in the other. Thus the individuals who tend to seek opportunity identification tend to have a modest $\mathrm{CE}$ orientation. A reliability coefficient of $p<0.0001$ was reported, indicating that this correlation is significant at a $1 \%$ level.

The correlation coefficient of the correlation between opportunity generation and exploitation and CE orientation indicates a low positive correlation coefficient of 0.19322 and represents the weakest correlation between the three factors observed. This particular correlation coefficient indicates that individuals who seek to generate and exploit opportunities within companies have a weaker drive towards CE orientation.

\section{Testing the statistically significant differences}

The chi-square test and T-test (Mann-Whitney $U$ test) were used to illustrate the statistically significant differences between the different variables and factors.

\section{One-sample chi-square test}

The one-sample chi-square $\left(x^{2}\right)$ test results are shown in Table 4 for the significant differences between individuals who frequently introduce innovations and individuals who never or rarely introduce innovations and their perceptions about different variables. 
Table 4: Chi-square test indicating the statistically significant difference for the frequency of introduction of innovation in companies by individuals

\begin{tabular}{|l|l|l|l|c|}
\hline \multirow{2}{*}{ Variable } & $\begin{array}{l}\text { Frequency of introduction of } \\
\text { innovation by individuals }\end{array}$ & $\begin{array}{l}\text { Chi-square } \\
\text { value }\end{array}$ & P-value \\
\cline { 2 - 3 } & Frequently & Never/rarely & & \\
\hline $\begin{array}{l}\text { Introduction of innovations by } \\
\text { company }\end{array}$ & 62 & 38 & 22.6617 & $<0.0001^{* * *}$ \\
\hline Level of risk taking & 62 & 38 & 0.0009 & 0.9758 \\
\hline Desire to achieve & 62 & 38 & 0.1247 & 0.7240 \\
\hline Commitment to experimentation & 62 & 38 & 8.3415 & $0.0154^{* *}$ \\
\hline
\end{tabular}

${ }^{* *}<0.05$ statistically significant difference $(95 \%$ confidence level)

$* * *<0.001$ statistically significant difference (99\% confidence level)

Table 4 shows there is a high chi-square score of 22.6 and a low p-value of 0.0001 respectively for the variables 'frequent introduction of innovation by individuals' and 'never or rare introduction of innovation by individuals', on their perception of the introduction of innovation by the company. The results thus show there is a statistically significant difference between the two variables, reflecting the differing opinions held by the frequent introducers and those who never or rarely introduce innovations. The study shows that the frequent introduction of innovation by the company could contribute towards introduction of innovation by individuals. This does not come as a surprise, as it was expected that the perception of innovation by individuals with frequent introductions would be higher than those who rarely or never introduced innovations. This is therefore statistically proven.

On the perception of the level of risk taking, a low chi-square score of 0.0009 and high p-value of 0.9758 was revealed for the variables 'frequent introduction of innovation by individuals' and 'never or rare introduction of innovation by individuals'. This result reflects no statistically significant difference between the variables tested of frequent innovators and less frequent innovators on their feeling towards a high level of risk taking. It had been expected that risk taking would be a dependent variable of introduction of innovations, but this could not be proven statistically.

The variables 'frequent introduction of innovation by individuals' and 'never or rare introduction of innovation by individuals' had a low chi-square score of 0.1247 and high p-value of 0.7240 , which indicates that there is no statistically significant differences between these variables with regard to their perception of the desire to achieve. This was surprising, bearing in mind that the level of achievement was thought to have a direct impact on innovations, but this could not be proven statistically.

The variables 'frequent introduction of innovation by individuals' and 'never or rare introduction of innovation by individuals' had a high chi-square score of 8.341 and low $p$-value of 0.0154 , which indicates that there is a statistically significant difference between these variables on the perception of commitment to experimentation. As was expected, the level of commitment to experimentation was high for the levels of introduction of innovation to the company, and this was proven statistically.

\section{The t-test}

The significance level for the three factors was carried out using the t-test and is reflected in Table 5 . The Mann-Whitney results portray a statistically significant difference for opportunity identification (0.0059) and opportunity generation and exploitation (0.0078). This means that the individuals who introduce innovation in the company commit themselves more to identifying opportunities and turning those opportunities into reality. This could be explained by the frequent introducers of innovation in the company being committed to experimentation and thriving in companies that introduce innovations. It is, however, surprising that risk taking and desire to achieve, which are regarded in literature as essential ingredients to innovation, were not statistically proven.

No statistical difference was noted for CE orientation (0.2517), as had been expected. Given the statistically significant differences noted above, CE orientation should thrive in an atmosphere where continual innovations are inherent. In this study, this was not the case. 
Table 5: T-test indicating the comparison of the three rotated factors with the level of individuals introducing innovations in the company

\begin{tabular}{|c|c|c|c|c|c|c|c|}
\hline \multirow{2}{*}{ Factors } & \multicolumn{2}{|c|}{$\begin{array}{l}\text { Introduction of } \\
\text { innovations }\end{array}$} & \multicolumn{2}{|l|}{ Mean } & \multicolumn{2}{|c|}{$\begin{array}{l}\text { Standard } \\
\text { deviation }\end{array}$} & \multirow[t]{2}{*}{ Mann Whitney } \\
\hline & 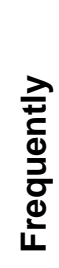 & 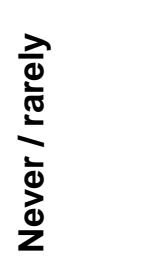 & 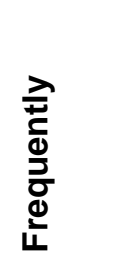 & 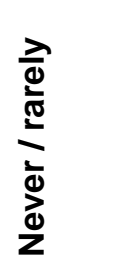 & 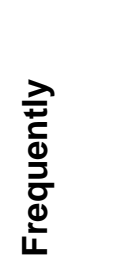 & 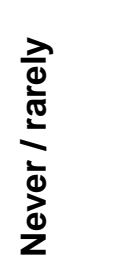 & \\
\hline $\begin{array}{l}\text { Opportunity } \\
\text { identification }\end{array}$ & 62 & 38 & 3.2339 & 3.0044 & 0.5486 & 0.5030 & $0.0059^{\star *}$ \\
\hline $\begin{array}{l}\text { Opportunity } \\
\text { generation and } \\
\text { exploitation }\end{array}$ & 62 & 38 & 2.8886 & 2.5622 & 0.5220 & 0.6809 & $0.0078^{\star \star}$ \\
\hline CE orientation & 62 & 38 & 3.3097 & 3.2561 & 0.4185 & 0.2918 & 0.2517 \\
\hline
\end{tabular}

** $<0.05$ statistically significant difference (95\% confidence level)

${ }^{* * *}<0.001$ statistically significant difference $(99 \%$ confidence level)

The t-test comparison of opportunity identification and the introduction of innovation by individuals in companies

Table 5 shows a comparison of opportunity identification and the level of introduction of innovations by individuals in the companies in which they work. The mean for Factor 1 (opportunity identification), when compared with the levels of individuals introducing innovations in the company, reveals a score of 3.2339 on a scale of 4.000 for those introducing innovation in the company frequently. This compares with 3.0044 on a scale of 4.000 for individuals who never or rarely introduce introductions in their company. These results indicate that the innovative individuals perceive themselves as having a relatively higher propensity towards identifying opportunities than the less innovative individuals. The variability of the results is measured by the standard deviation. The variability is rather high at 0.54 and 0.50 for frequent introducers and less frequent introducers respectively. The comparison between frequent and rare introduction of innovation by individuals (introduction of innovations) on their perception of opportunity identification revealed a statistically significant difference between the two variables.

The t-test comparison of opportunity generation and exploitation and introduction of innovation by individuals in companies

The comparison of the relationship between opportunity generation and exploitation and the level of introduction of innovations by individuals, from the responses received, is presented in Table 5 . The means for Factor 2 (opportunity generation and exploitation) is compared with the levels of individuals introducing innovations in the company frequently, rarely or never. This returns a score of 2.8886 on a scale of 4.000 , and 2.5622 on a scale of 4.000 for frequent innovators and less frequent innovators respectively. This reflects the general tendency of innovative individuals to seek to ensure that opportunities identified are exploited, unlike the individuals who rarely or never make such innovations. The variability is, however, rather high at 0.5220 and 0.6809 for frequent and less frequent innovators respectively. Statistically significant differences were found between innovative individuals and less innovative individuals as regards their perception of opportunity generation and exploitation. Innovative individuals see getting ideas on how to make innovations better and implementing innovative ideas as highly important. Organisational processes are also seen as very important.

The t-test comparison of corporate entrepreneurial orientation and introduction of innovation by individuals in companies

The factor CE orientation compared with the level of introduction of innovations by individuals in the companies in which they work is presented in Table 5. The mean for Factor 3 (CE orientation) has a 
score of 3.3097 on a scale of 4.000 and 3.2561 on a scale of 4.000 for individuals who frequently introduce introductions and those who never or rarely do so, respectively. The innovative individuals seem to have a higher CE orientation than those who are not innovative. The variability is rather high at 0.532 and 0.0473 for frequent introducers and rare introducers, respectively. No statistically significant difference was found between introduction of innovations by individuals and CE orientation. Significant differences were found between the two groups with regard to their perception of CE orientation. Barriers to developing CE orientation in a company are seen to moderately affect the company when focusing on the control systems, organisation structure, policy procedures and strategic direction.

\section{DISCUSSION OF FINDINGS}

Strong support was found for Hypothesis 1, but no support for Hypothesis 2. On the basis of the tests and the empirical results achieved, the following conclusions can be drawn regarding the testing of the two hypotheses:

- Hypothesis 1: The null hypothesis is rejected and the alternative one accepted.

- Hypothesis 2: The null hypothesis is accepted and the alternative one rejected.

This indicates that in general the establishment of CE orientation does have a significant impact on the pursuit of innovation streams. The results thus show that companies with an inherently high CE orientation receive a higher benefit from the exploitation of innovation, which improves the rate of innovation flows in the companies. In this study, the significant average responses by those individuals who had a low perception of innovative factors negated the optimisation of these innovations. This is interesting, as there could be other factors that inhibit innovation streams within company boundaries. The inhibition of the levels of innovation introduced could be attributed to the barriers to CE, which were noted as moderate.

The results of this paper clearly highlighted the importance of stimulating the pursuit of innovation through $\mathrm{CE}$ orientation. An interesting observation was made by establishing whether the innovative process inherent in corporate companies in Botswana arises as an end result or conduit of CE orientation. The magnitude of this effect shows CE orientation as having a catalytic effect, in that it is a prerequisite for the pursuit of innovation. For companies in Botswana to be innovative, it is therefore necessary for CE orientation to become part of the company's culture, and attention should be paid to the elimination of barriers to CE orientation.

\section{CONCLUSION}

The paper considered the promotion of CE orientation as a means to encourage corporate individuals to be innovative. It presented a framework with the related variables which were used in linking the CE orientation to the pursuit of innovation within corporate borders. The results showed that there is CE orientation in Botswana which leads to the pursuit of innovation. However, the level of innovation is affected by the low perception of the innovation process (opportunity identification, generation and exploitation). Three factors were generated from factor analysis performed on different variables, namely opportunity identification, opportunity generation and exploitation and CE orientation. This paper hopes to make a significant contribution to the field of CE orientation in Africa, as no other studies have been done in this particular subject area in Botswana. Consequently, there is no secondary data available, which makes comparison of the study results difficult.

This study made pertinent empirical observations which suggest that:

- There is a link between CE orientation and the pursuit of innovation in corporate boundaries as a conduit for enhancing entrepreneurial activity in companies. The integration of the innovation process and entrepreneurship actions produces synergy that propels the companies' ability to adapt, develop and innovate.

- For optimal CE orientation, the company needs to establish systems and structures that are not counterproductive to the encouragement of $\mathrm{CE}$ inherent in an entrepreneurial company. The company must make it possible to act entrepreneurially within its organisational systems without hindrance. 
- $\quad$ EE manifests itself in established companies through individual, team and organisational processes that require continuous assessment and development. Certain prerequisites are necessary for CE orientation to be embedded in corporate companies in the form of innovativeness, risk taking, proactiveness, need for achievement, autonomy and focused knowledge.

This research therefore determined that, within corporate boundaries, CE activities imposed through CE orientation could largely integrate with the innovative capacity arising from individual initiative. It also determined that large corporate firms can become entrepreneurial companies by encouraging and developing entrepreneurship within the company. If entrepreneurship is embedded in individuals within a company's boundaries, the pursuit of innovation is strengthened. The individual who is committed to pursuing innovation must be afforded the opportunity to do so. The innovation process must therefore be legitimised in all respects to open the company to the exploration and exploitation of innovation. Future studies could focus on the hierarchical position (which was not a focus of this study), investigating how the responses on the pursuit of innovation compare for CEOs and management-level employees.

\section{REFERENCES}

Antoncic, B \& Hirsh, RD, 2003. Clarifying the intrapreneurship concept. Journal of Small Business and Enterprise Development 10(1), 7-24.

Athayde, R, 2003. Measuring young people's attitudes to enterprise. www.kingston.ac.uk/sbrc Accessed 21 May 2008.

Bolton, B \& Thompson, J, 2000. Entrepreneurs: Talent, temperament and technique. ButterworthHeinemann, Oxford.

Burns, P, 2005. Corporate entrepreneurship: Building an entrepreneurial organisation. Palgrave, New York.

Cantillon, R, 1931[1755]. Essai sur la nature du commerce en general. English translation, with other material, by Henry Higgs, 1931. Macmillan, London.

Carter, S \& Jones-Evans, D (Eds), 2000. Enterprise and small business: Principles, practice and policy. Prentice Hall/Pearson Education, Harlow.

Christensen, KS, 2004. A classification of corporate entrepreneurship umbrella: Labels and perspectives. International Journal of Management Enterprise Development 1(4), 301-15.

Covin, JG \& Slevin, DP, 1991. A conceptual model of entrepreneurship as a firm behaviour. Entrepreneurship Theory and Practice 16(1), 7-25.

Dess, GG \& Lumpkin, GT, 2001. Linking two dimensions of entrepreneurial orientation to firm performance: The moderating role of environment and industry live cycle. Journal of Business Venturing 16(5), 429-51.

Dess, GG \& Lumpkin, GT, 2005. Entrepreneurial orientation as a source of innovative strategy. In Floyd, SW, Roos, J, Jacobs, CD \& Kellermanns P (Eds), Innovating strategy process. Blackwell, Oxford.

Diamantopoulos, A \& Schlegelmilch, BB, 2000. Taking the fear out of data analysis. Thomson Learning, London.

Dovey, K \& White, R, 2005. Learning about learning in knowledge-intense organisations. The Learning Organisation 12(3), 246-60.

Drucker, PF, 2001. Selections from the management works of Peter F Drucker. Butterworth-Heinemann, Woburn.

Ferreira, J, 2002. Corporate entrepreneurship: A strategic and structural perspective. Proceedings of the 47th World Conference of the International Council for Small Business, June, San Juan, Puerto Rico, Argentina. 
Fiet, JO, 2002. The systematic search for entrepreneurial discoveries. Quorum Books, Westport.

Fynn, CA, 2005. A founder's strategy and entrepreneurial leadership are critical elements in growing and developing a midsized venture. DPhil (Entrepreneurship) thesis, Department of Business Management, University of Pretoria, South Africa.

Hisrich, RD, Peters, MP \& Shepherd, DA, 2004. Entrepreneurship. Sixth edition. McGraw-Hill/ Irwin, Boston.

Hornsby, JS, Kuratko, DF \& Zahra, SA, 2002. Middle managers' perception of the internal environment for corporate entrepreneurship: Assessing a measurement scale. Journal of Business Venturing 17(3), 253-73.

Ireland, RD, Hitt, M \& Sirmon, DG, 2003. A model of strategic entrepreneurship: The construct and its dimensions. Journal of Management 29(6), 963-89.

Kuratko, DF \& Welsch, HP, 1994. Entrepreneurial strategy: text and cases. Dryden, Fort Worth.

Kuratko, DF, Montagno, RV \& Hornsby, JS, 1990. Developing an intrapreneurial assessment instrument for an effective corporate entrepreneurial environment. Strategic Management Journal 11(Summer Special Issue), 49-58.

Lumpkin, GT \& Dess, GG, 1996. Clarifying the entrepreneurial orientation construct and linking it to performance. The Academy of Management Review 21(1), 135-72.

Mbendi Information Services, 2008. Botswana: An overview. www.mbendi.co.za/land/af/bo/p0005.htm\#20 Accessed 7 May 2008.

McClelland, DC, 1976. The achieving society. Irvington, New York.

McFadzean, E, O'Loughlin, A \& Shaw, E, 2005. Corporate entrepreneurship and innovation Part 1: The missing link. European Journal of Innovation Management 8(3), 350-72.

McGrath, RG \& Macmillan, I, 2000. The entrepreneurial mindset: Strategies for continuously creating opportunity in an age of uncertainty. Harvard Business School Press, Boston.

Ministry of Commerce and Industry, 1999. Policy on Small, Medium and Micro Enterprises in Botswana. Government Printer, Gaborone.

Morris, MH \& Kuratko, DF, 2002. Corporate Entrepreneurship. Harcourt College Publishers, Orlando. Mourdoukoutas, A \& Papadimitriou, BB, 2002. Taking the fear out of data analysis. Thomson, London.

Nieman, GH \& Pretorius, M, 2004. Managing growth: A guide for entrepreneurs. Juta, Cape Town. Pavitt, K, 2005. Innovation process. In Fagerberg, J, Mowery, DC \& Nelson, RR (Eds), The Oxford Handbook of Innovation. Oxford University Press, New York.

Pinchot, G, 1985. Intrapreneuring: Why don't you leave the company and become an entrepreneur? Harper \& Row, New York.

Rauch, A, Wiklund, J, Frese, M \& Lumpkin, GT, 2004. Entrepreneurial orientation and business performance: Cumulative empirical evidence. In Zahra, SA, Brush, CG, Davidsson, P, Fiet, J, Greene, PG, Harrison, RT, Lerner, M, Mason, C, Meyer, GD, Sohl, J \& Zacharakis, A (Eds), Frontiers of entrepreneurship research. Arthur M Blank Centre for Entrepreneurship, Babson College, Massachusetts.

Struwig, M, 2003. In Nieman, GH, Hough, J \& Nieuwenhuizen, C (Eds), Entrepreneurship: A South African perspective. Van Schaik, Pretoria. 
Thompson, JL, 2004. Innovation through people. Management Decision 42(9), 1082-94.

Thornberry, NE, 2003. Corporate entrepreneurship: Teaching managers to be entrepreneurs. Journal of Management Development 22(4), 329-44.

Timmons, JA \& Spinelli, SS, 2003. New venture creation: Entrepreneurship for the 21st century. Sixth edition. McGraw-Hill, New York.

Voss, ZG, Voss, GB \& Moorman, C, 2005. An empirical examination of the complex relationships between entrepreneurial orientation and stakeholder support. European Journal of Marketing 39(9/10), 1132-50.

Zahra, SA, 1996. Governance, ownership, and corporate entrepreneurship: The moderating impact of industry technological opportunities. Academy of Management Journal 39(6), 1713-35.

Zhao, F, 2005. Exploring the synergy between entrepreneurship and innovation. International Journal of Entrepreneurial Behaviour and Research 11(1), 25-41.

Zikmund, WG, 2003. Business research methods. Seventh edition. Thomson South Western, Mason.

Zimmerer, TW \& Scarborough, NM, 1996. Entrepreneurship and the new venture formation. PrenticeHall, New York. 